\title{
The Historical and Structural Context for the Proposed Changes to ABET Accreditation Criteria
}

\section{Dr. Atsushi Akera, Rensselaer Polytechnic Institute}

Atsushi Akera is an Associate Professor in the Department of Science and Technology Studies at Rensselaer Polytechnic Institute (Troy, NY). He received his M.A. and Ph.D. in the History and Sociology of Science, University of Pennsylvania. His current research is on the history of engineering education reform in the United States (1945-present). He is Immediate Past Chair of the ASEE Liberal Education / Engineering and Society Division, and the current Lead for the "Connecting Us" Team of the ASEE Board's Strategic Doing Initiative. He is a former member of the Society for the History of Technology's (SHOT) Executive Council, and Associate Editor of the international journal, /Engineering Studies/. His publications include /Calculating a Natural World: Scientists, Engineers and Computers during the Rise of U.S. Cold War Research/ (MIT Press, 2006). 


\title{
The Historical and Structural Context for the Proposed Changes to ABET Accreditation Criteria
}

\author{
Consider the following quote by the 1950 ASEE President, Thorndike Saville:
}

"Times change men and men with them": So also must education change to prepare men to cope with changing times. ... Engineering education is the most complex and the most sensitive to social and political considerations of any of the professional disciplines.... this Society has always been prompt to relate the basic premises and curricula of engineering education to realistic appraisals of changing times and needs. ${ }^{1}$

Taken at face value, this statement suggests that engineers situate their knowledge claims somewhat differently from the other professions. Based on an instrumental conception of knowledge, engineers, instead of claiming simple jurisdiction over an esoteric domain of knowledge, inextricably link their professional identity to an obligation, and indeed a cultivated responsibility for adapting their knowledge to changing times and needs. Over the decades, these changes have reoriented engineering education in rather different directions, from embodied knowledge, to cooperative education, engineering science, social responsibility, design, and innovation, often in distinct combinations. Put formally, engineers may in fact possess an ethnomethodologically accountable - if also evolving and non-monolithic - body of practice for reexamining the epistemological foundations of their discipline and realigning it to match their perceptions of an ever changing social and economic environment. ${ }^{2,3,4}$

Given the broad concern expressed about "process" associated with the proposed changes to ABET Criteria $3 \& 5$, this ought to be sufficient reason for studying this body of practice for engineering education reform. However, to fully appreciate what drives these proposed changes in accreditation standards, we need to understand not only the practice of engineering education reform, but the underlying structural conditions that both enable and constrain these practices. In thus melding, albeit through a rather uncomfortable wedding, a Giddensian perspective on structure-agency dualism with an ethnomethodological outlook towards practice, we consider here the question of what gives shape to engineering educational reforms as achieved through a focus on accreditation., 6

This is a study which we are preparing for, and what we report here are simply the results of our preliminary analysis. However, the background information that we've gathered already allows us to provide engineering educators with an answer as to why, despite all the effort, engineering education has proven to be such an intractable or at least insoluble problem, on characterized by constant shifts in content as well as pedagogy and means of program evaluation. This is an answer that requires multiple layers of explanation that involved an understanding of U.S. academic institutions, engineering professional identities, and the epistemic traditions of engineering itself. It is our contention that without this background knowledge, engineering educators are bound to "repeat the errors of the past," a phenomenon that polite observers have already noted to be an endemic problem in engineering education. ${ }^{7}$ While this knowledge will not result in a single answer to the "problem" of engineering education, our hope is that it will provide engineering educators and administrators with the beginnings of a more reflexive set of tools for carrying out proper deliberations about contemporary options for reform. We believe this knowledge is necessary for all of ABET's constituencies, including ABET's own delegates and officials, to begin crafting accreditation standards in an enduring and effective mode. With due haste, it would include the possibility of helping engineering educators evaluate the latest set of recommended changes. 


\section{The Underlying Structure of U.S. Engineering Education}

Engineering education in the United States is a surprisingly complex institution. Consider, for starters the fact that we have engineering degree programs at public and private colleges; general universities, dedicated engineering schools, and liberal arts colleges; and rely on an articulated system that includes community colleges and extends into various opportunities for continuing professional development and graduate study. We can add to this the fact that we have 50 separate state systems of higher education, significant regional variation in industrial capacity and workforce needs, and a variety of federal programs and policies not the least of which is the federal government's major investments in scientific and engineering research. While scholars such as Ken Alder have noted how institutional diversity exists even in state-centered systems of engineering education as found in France, it is the significant "marketorientation" of the U.S. system of that makes it a productive engine for generating new knowledge and for producing a highly versatile and skilled workforce. ${ }^{8}$ By the same token, this diversity creates a situation that is difficult both to regulate and transform.

Simply put, engineering education is not a problem that can be solved. This already follows from the above discussion about engineering's epistemic commitment to change engineering to serve "changing times and needs," which is then complicated by the dynamic forces that drive the response in different directions. Yet, a separate set of epistemic habits within engineering compel many engineering educators to approach their task with the often elusive hope of solving "the problem" of engineering education through innovative programs and curricula. This is not to say that we haven't made valuable progress in specific areas. Nevertheless, in translating the overall situation into the language of engineering itself, we should regard engineering education to be a dynamic system that is in need of constant adjustment in response to changes in the social and economic context. We need to acknowledge that engineering education is a field in which we will face perpetual cycles of reform.

The realization that engineering education requires constant attention is, however, no guarantee that we know how to do it well. Few engineering educators are trained in engineering education, let alone in the social sciences. Yet, transforming engineering education to serve an evolving social context requires just such a skill set. Given that our work emerges out of the grounded theory tradition, we would be the first to recognize that engineering educators and administrators have amassed considerable knowledge about how to operate in complex institutional settings. ${ }^{9}$ Nevertheless, it is also one of our goals to make our own expertise in the social sciences - especially historical analysis and institutional sociology-more relevant to the engineering education community through greater collaboration.

This focus on disciplinary habits also reminds us of Seron and Silbey's recent findings regarding riskaverse behavior among engineers and engineering educators. Seron and Silbey describe what they refer to as Type II errors of over-specification, which they find within engineering education. Their article, "The dialectic between expert knowledge and professional discretion," focuses on quantitative accreditation standards and how they adversely impact an emphasis on professional judgment in engineering. ${ }^{10}$ And although EC 2000 was an attempt to move beyond quantitative standards, the implementation of "a-k" outcomes and their assessment merely affirm Seron and Silbey's findings. For many, this list simply became a different set of requirements to be met, rather than a change that would enable genuine educational innovation - a specific critique offered by the ABET Engineering Accreditation Commission's (EAC's) Criterion 3 Task Force (TF-3). The obdurate habit of over-specification can simply manifest itself in different ways - although we ought to consider in the same light TF-3's own recommendation to include within Criterion 3 only those outcomes that can be reliably achieved. ${ }^{11}$

As already alluded to above, what stymies effective solutions in engineering education is hardly limited to the disciplinary habits and boundaries of engineering; the reasons go back to the structure of U.S. educational institutions and the engineering profession itself. With regards to the latter, engineers should 
stop worrying that theirs is somehow an incomplete profession. Sociologists have long ago abandoned the idea that medicine and law are ideal typical professions. If anything, they are ideal atypical professions that continue to haunt the conduct of other professions, including engineering. Especially from the point of view of the system-theoretical take on the professions promulgated by Andrew Abbott (as based in turn on earlier studies of the professions by symbolic interactionists), professional standing is now generally considered to be a relational attribute, something conferred by other individuals and organizations through well recognized - and sometimes less recognized - paths for acknowledging and granting jurisdiction over esoteric knowledge and expertise. ${ }^{12,13}$ Thus, although engineers did face some jurisdictional challenges during the profession's origins, and again during the management profession's stellar ascent in the $1920 \mathrm{~s},{ }^{14}$ their position has been reasonably secure since the start of the Cold War. The augmented demand for scientific and engineering talent, paired with the further reification of an applied science ideology, introduced new patterns of professional labor mobility that contributed substantially to the engineer's standing. Simply put, it was less expensive for the oligopolistic firms in STEM-based industries to treat engineers as professionals, as opposed to paying the full market value for their labor. Engineers in turn accepted the deal since throughout much of the Cold War era, engineering was a common path for upward social mobility; individuals derived as much value from the autonomy and status accorded to them as professionals (control of their own work hours; an internal system of promotion administered by peers; right to publish; resources given for professional travel and development) as through higher salaries - already high enough for them to enjoy new suburban lifestyles and its associated pleasures. These patterns have generally continued.

The basic professional configuration of engineering in the United States has also been shaped in other ways. Perhaps most notable is the influence of our land grant institutions. While the goal of producing an augmented industrial workforce in applied science and, originally, the "mechanic arts" might be judged conservative by contemporary political standards, it also served the liberal mission of opening up educational access; along with other measures such as the G.I. Bill, land-grant institutions did much to "democratize" higher education, even as this ensured that a strong program in general education would be a common imprint not only at state universities, but all U.S. engineering degree programs. But by the same token, political limits to state commitments to higher education in the U.S. have tended to "freeze" engineering education in a four-year undergraduate model. Yet, this basic arrangement dovetails not only with industry's continuous desire to maintain a large STEM workforce-with correspondingly lower wages - but their ability, outside of P.E. registration, to confer professional standing through meritocratic standards for promotion constructed within each firm and industry. The overall result of these structural conditions is familiar to all those in engineering: In the U.S., we see a high degree of disciplinary fragmentation along with a significantly permeable boundary between engineering and management. Regional variation as well as variation by industry somewhat complicates this picture. ${ }^{15}$

Meanwhile, there is one other distinct feature of engineering education (not unique to the U.S.) that has to do with the place of engineering educators within engineering's professional configuration. As is well known, engineering schools relied on full-time educators instead of practitioners from early on. While the research-orientation of many faculty following World War II may have weakened faculty commitments to teaching, many engineering faculty nevertheless share a primary occupational identification as educators alongside their disciplinary identities. As a consequence, engineering educators have tended to exert a centripetal influence on engineering education favoring, for example, a stronger emphasis on fundamentals and breadth when compared to many of their professional counterparts. ${ }^{16}$ As compared to a field like medicine, however, the profession's control over educational content remains incomplete. While ABET, and its precursor, the Engineers' Council for Professional Development (ECPD) have been the principal agencies for the control of engineering curricula at least since the late 1960s, they have done so through an explicit model of shared decision-making. Indeed, ECPD was first set up as a "conference style" organization in full recognition of the fact that different constituencies, including the professional 
societies, ought to have a seat at the table. This basic approach to educational governance continues in the system of delegates who are assigned to ABET today. ${ }^{17}$

Finally, when this is paired with the academic tradition of tenure, you get one more relevant phenomenon. Given that basic reforms in engineering education occur on a cycle of about 15-20 years, and the fact that academic tenure exceeds this interval, universities have, at any given time, individuals with very different commitments to reform. And while some areas, such as surveying or even shop courses have faded or died away, other old traditions, such as engineering drawing, have pursued successful reconversion strategies for reinventing their domain-first as descriptive geometry, and then as computer-assisted design (CAD) in the case of engineering drawing. When you place on top of this the successive waves of technical specialization, a basic orientation towards general education, and a (nominal) commitment to a four year curriculum, it is no wonder that engineering suffers from a highly compacted curriculum with so little room to maneuver.

At least since the time of the Wickenden Investigations in the 1920s, many, especially those affiliated with elite institutions and land-grant universities, have declared that the proper "scope" of undergraduate engineering education ought to be the underlying preparation for professional practice-meaning basic training in breadth and the fundamentals - as opposed to direct preparation for professional practice. ${ }^{18,19}$ Large employers and their personnel departments have generally supported this position, given that they do prefer to see engineering graduates as a human resource that they can mold to their specific purposes; hiring those with bachelor's degrees at the entry level also doesn't preclude hiring those with Master's degrees and PhDs as needed. On the other hand, small to medium industries have rather different employment traditions and labor requirements, and there are also notable regional differences and industry-specific requirements with regards to STEM workforce needs. Disciplinary differences, as well as historical contingencies in the formation of engineering professional societies, and the difference between elite and non-elite universities add further complexity to the mix.

\section{Educational Governance and An Evolving Pattern of Reform: Opening Up the Inquiry}

It is little wonder, then, that concerns about "process" emerge so quickly within the arena of engineering education. This has been true in the past, as well as in the present situation. ${ }^{20}$ At the root of the matter is the question of what social scientists refer to as educational governance. There are basic questions to be asked about who is given a seat at the table, how the conversation is structured, and who is able to shape the dialogue, and how. If engineering organizations like ASEE and ABET, and their precursors, managed to bring different interests into alignment, it has been through their use of a successful process for manufacturing consent.

This brings us back to our original point of departure, namely, a focus on the practice of engineering education reform. What does this body of practice look like? From the historical record, what we know so far is that engineering education reform emerged out of the broader educational reform traditions of the Progressive Era, as well as the engineers' own direct involvement with Progressive Era reforms. Aided especially by the Carnegie Foundation for the Advancement of Teaching, the American Society for Engineering Education (ASEE) and its precursor, the Society for the Promotion of Engineering Education, internalized an investigation tradition built on familiar practices such as survey research, site visits, and the enlistment of objective experts hired to carry out an investigation. During mid-century, however, internal fissures within the engineering profession and among the engineering schools caused the primary decision-making authority to shift from ASEE to ECPD. With it, the voluntary traditions of investigation and society-wide deliberation that characterized ASEE's grand investigations gave way to the more mediated conversations carried out within the particular governance structure set up for the ECPD, which continues at least in form with ABET. ${ }^{21}$ 
However, the process employed by ABET to review and revise its accreditation criteria has not been fixed, nor does the process simply mirror its formal organizational structure. For example, the core ideas and vision for EC 2000 emerged through direct collaboration between the National Academy of Engineering (NAE), the National Science Foundation's Engineering Directorate, and ABET. ${ }^{22}$ By contrast early accounts indicate that the current set of proposed changes emerged out of what was more of an internal review process, set up within the organizational and bureaucratic machinery of the Engineering Accreditation Commission (EAC). As a result, key ideas for change were more bottom up in their origin, stemming at least in part from the difficulties and frustrations encountered by EAC program evaluators as well as schools that faced difficulties during accreditation.

Lest this be construed as a critique of the original task force, we fully recognize the thoughtful and deliberative processes that went into producing the current set of proposed changes. Facing mounting concerns about accreditation outcomes, and the fact that they had gone through two full accreditation cycles since the origins of EC 2000, the EAC's Criteria Committee (CC) set up a Criterion 3 Task Force (TF-3) in 2009 to carry out a reevaluation of Criterion 3. The task force had been instructed to survey specified constituencies and to analyze the data pertaining to accreditation outcomes. While there may be some questions as to whether all of the relevant constituencies were consulted, the task force amassed through this process no less than 75 recommended additions to Criterion 3. Its analysis of evaluation outcomes meanwhile suggested not only that the struggles over meeting the many outcomes-especially those associated with the so-called "soft skills"-were not only hindering innovation, but producing inconsistencies in evaluation outcomes. While the following is speculative, it seems plausible that it was in recognizing the impossibility of incorporating the recommended additions to Criterion 3 that TF-3 considered the radical alternative of reducing the number of learning outcomes, specifically to allow programs to experiment with the introduction of some of the proposed additional criteria through more serious engagement with program-specific criteria.

This basic process, as well as the underlying concerns that drove the current reevaluation is described in publicly available documents as well as statements issued by ABET. ${ }^{23}$ But again, the issue is not simply about transparency. We know from both the field of Science and Technology Studies as well as organizational sociology that official accounts can mask the more elaborate set of conversations that give rise to new policy positions; meanwhile even close adherence to a process can have implications we need to consider since the specified process can favor certain constituencies. Assuming that we are not content to simply delegate decisions about accreditation standards to ABET itself, each constituency of ABET has to be able to read these implications through a better understanding of the process.

While this detailed understanding of process is the major objective of the study that we have yet to amass data for, we can at least demonstrate the consequence of a difference in process by comparing the two versions of the proposed changes that we have seen so far. An initial reading of TF-3's original "1-6" Criterion 3 student learning outcomes that the task force put forward as an alternative to "a-k" reveals the following commitments: ${ }^{11}$

- A strong linear model of applied science

- A tendency to view engineering as an experimental, laboratory-based discipline.

- The recognition, on the other hand, of a greater need for integration if engineering graduates are to effectively utilize their skills in engineering practice.

- Related to this, a stronger articulation of engineering as a design process that begins with problem formulation; analysis and synthesis; and testing.

- Likewise, a shift towards a more instrumental view of the humanities and social sciences, with a specific call for evaluating all so-called "soft skills" in the context of professional practice. 
- The elimination of other, especially "soft skills" deemed to be difficult to assess, or else their transfer to Criterion 5 (curriculum), thus exempting these skills from detailed student outcomes level assessment.

Although the EAC Criteria Committee tasked TF-3 to carry out the initial investigation, the committee did not abrogate its responsibility to review the task force's recommendations. Also taking in feedback from a mandated extra round of input, the Criteria Committee came up with a revised criteria that it presented to the EAC. The current, proposed "1-7" criteria, along with language placed in a new introduction and through changes to Criterion 5, point to the stronger professional orientation of those on the Criteria Committee. Their recommendations reveal the following commitments: ${ }^{24}$

- A reassertion of engineering as itself a fundamental body of knowledge, in what may have been an oversight on the part of TF-3.

- A slight softening of its commitment to the scientific and experimental nature of engineering by rejecting the special place accorded to testing by TF-3.

- A new focus on engineering judgment and professional judgment; a restored emphasis on professional responsibility, including the graduate's ability to make informed, ethical decisions based on the global, economic, environmental, and societal impact of engineering.

- The reintroduction of lifelong learning, but as operationalized to facilitate reliable assessment.

- Also, the reintroduction of a more robust set of constraints on the engineering design process, but as handled as definitions placed in an expanded introduction.

- Likewise, the introduction of a new focus on diversity, and a renewed emphasis on globalization, both also in the introduction.

It would be interesting to know whether members of TF-3 consider the revised criteria a compromise, one that impacts the efficacy of their recommendations. Nevertheless, the revised criteria retains key aspects of the original recommendations including the focus on integration; defining learning outcomes narrowly around professional practice; and a reduced set of outcomes designed to foster educational innovation and more consistent evaluation outcomes.

The point is not that one criterion is better than the other; for example, in light of past discussions about the proper scope of undergraduate training, the current emphasis on professional judgment may exceed what is possible in an undergraduate curriculum. The point is instead that different standards can emerge out of different constituents and processes. Both require careful attention by any constituency with an interest in evaluating the proposed changes, including the pedagogic implications embedded within the proposed changes. We hope, through our continued inquiry, to provide the underlying historical and social scientific analyses necessary for this kind of evaluation to occur, both with respect to the current set of proposed changes, and other changes that surely lay ahead in the future.

\section{Notes}

\footnotetext{
${ }^{1}$ Saville, Thorndike (1950-1951). Engineering education in a changing world, Journal of engineering education 41 : 4-10, 4.

${ }^{2}$ Garfinkel, Harold (1967). Studies in ethnomethodology. Englewood Cliffs, N.J.: Prentice Hall.

${ }^{3}$ Heritage, John (1984). Garfinkel and ethnomethodology. Cambridge: Policy Press.
} 
${ }^{4}$ Lynch, Michael (1993). Scientific practice and ordinary action: ethnomethodology and social studies of science. Cambridge: Cambridge University Press.

${ }^{5}$ Giddens, Anthony (1993). New rules of sociological method: a positive critique of interpretive sociologies. Stanford, Calif.: Stanford University Press.

${ }^{6}$ Giddens, Anthony (1984). The constitution of society: outline of the theory of structuration. Berkeley: University of California Press.

${ }^{7}$ See for instance, Seely, Bruce E. (2005). Patterns in the history of engineering education reform: a brief essay, in National Academy of Engieering, Educating the engineer of 2020: adapting engineering to the new century, 114-130. Washington, D.C.: National Academies Press.

${ }^{8}$ Alder, Ken (1997). Engineering the revolution: arms and Enlightenment in France, 1763-1815. Princeton, N.J.: Princeton University Press.

${ }^{9}$ Glaser, Barney G. and Anselm L. Strauss (1967). The discovery of grounded theory: strategies for qualitative research. Chicago: Aldine Publishing Co.

${ }^{10}$ Seron, Carroll and Susan S. Silbey (2009). The dialectic between expert knowledge and professional discretion: accreditation, social control and the limits of instrumental logic, Engineering studies 1/2: 101-127.

${ }^{11}$ ABET (2014). Proposed revisions to ABET criterion 3 (student outcomes [a-k]) and criterion 5 (curriculum). Online, http://www.ecedha.org/docs/default-source/2015-speaker-presentations/abet-workshopslides.pdf?sfvrsn=0 (Retrieved 11/18/2015).

12 Abbott, Andrew D (1988). The system of professions: an essay on the division of expert labor. Chicago: University of Chicago Press.

${ }^{13}$ Larson, Magali S. (1977). The rise of professionalism: a sociological analysis. Berkeley: University of California Press.

${ }^{14}$ Noble, David F. (1977). America by design: science, technology, and the rise of corporate capitalism. New York: Knopf.

${ }^{15}$ One of the best historical descriptions of the engineering profession remains Layton, Edwin T. (1986). The revolt of the engineers: social responsibility and the American engineering profession. Baltimore: Johns Hopkins University Press.

${ }^{16}$ Akera, Atsushi and Bruce Seely. (2015). A historical survey of the structural changes in the American system fo engineering education, in International perspectives on engineering education. Volume 1, Engineering education practice and context. Steen Hyldgaard Christensen, Christelle Dider, Andrew Jamison, Martin Meganck, Carl Mitcham, and Byron Newberry, eds. New York: Springer. 7-32.

${ }^{17}$ For ABET's current governance structure, see ABET (2016). Governance. http://www.abet.org/aboutabet/governance/ (Retrieved 1/31/2016).

${ }^{18}$ Society for the Promotion of Engineering Education (1930). Report of the investigation of engineering education, 1923-1929, Volume I. Pittsburgh, Pa.: Lancaster Press.

${ }^{19}$ Society for the Promotion of Engineering Education (1940). Report of Committee on Aims and Scope of Engineering Curricula. Journal of engineering education 30:555-566.

20 See, for starters, Reynolds, Terry S. and Bruce Seely (1993). Striving for balance: a hundred years of the American Society for Engineering Education, Journal of engineering education 82:136-151.

${ }^{21}$ Akera, Atsushi. (2008). Understanding the practice of engineering education reform: the investigative traditions of the American Society for Engineering Education, 1907-1968. Paper, ASEE annual meeting, June 2008. Pittsburgh, Pa.

${ }^{22}$ Akera, Atsushi and Bruce Seely. (n.d.) Liberal learning revisited: engineering and liberal arts integration and the consequences for SHOT. Unpublished manuscript in author's possession, 28-29.

23 See esp. ABET (2014), n. 11 above, and ABET (2015). Rationale for revising criteria 3 and 5. Accreditation alerts. Online. http://www.abet.org/accreditation/accreditation-criteria/accreditation-alerts/rationale-forrevising-criteria-3/ (Retrieved 11/11/2015).

${ }^{24}$ ABET (2016). Proposed revisions to criteria for accrediting engineering programs definitions, general criterion 3 student outcomes, and general criterion 5 curriculum. Online. http://www.abet.org/wpcontent/uploads/2015/11/Proposed-Revisions-to-EAC-Criteria-3-and-5.pdf (Retrieved 1/31/2016). 